\title{
Medical visits, antihypertensive prescriptions and medication adherence among newly diagnosed hypertensive patients in Korea
}

Hyoseon Jeong ${ }^{1}$, Hyeongsu Kim ${ }^{1 *}$, Kunsei Lee ${ }^{1}$, Jung Hyun Lee ${ }^{1}$, Hye Mi Ahn ${ }^{1}$, Soon Ae Shin ${ }^{2}$ and Vitna Kim³

\begin{abstract}
Objectives: The objective of this study was to assess the antihypertensive medication adherence in patients who were newly diagnosed with hypertension in Korea.

Methods: Study subjects were diagnosed with hypertension for the first time by the General Health Screening in 2012 and were 65,919. As indices, visiting rate to medical institution, the antihypertensive prescription rate, medication possession ratio and the rate of appropriate medication adherence were used. The qualification data, the General Health Screening data and the health insurance claims data were used.

Resutls: Visiting rate to medical institution within one-year was $42.3 \%$. Gender, age, family history of hypertension, smoking status, drinking frequency, insurance type, BMI, hypertension status, blood glucose level and LDL-cholesterol level were significant variables for visiting a medical institution. Of the study subjects who visited a medical institution, the antihypertensive prescription rate was $89.1 \%$. Medication possession ratio was $70.9 \%$ and the rate of appropriate medication adherence was $60.6 \%$. Age, family history of hypertension, smoking status, BMl level, hypertension level, blood glucose level, status, and LDL-cholesterol level were significant variables for the antihypertensive prescription and gender, age, family history of hypertension, smoking status, BMI, hypertension status, and the time of the first visit to a medical institution were significant variables for appropriate medication adherence.
\end{abstract}

Conclusions: This study showed that the antihypertensive medication adherence in patients who were newly diagnosed with hypertension was not relatively high in Korea. National Health Insurance Service should support an environment in which medical institutions and those diagnosed with hypertension can fulfill their roles.

Keywords: Hypertension, Mass screening, Medication possession ratio, Medication adherence

\section{Introduction}

Hypertension is a primary risk factor of myocardial infarction and stroke [1], and $29.2 \%(28.8-29.7 \%)$ of the world's population is predicted to have hypertension by 2025 [2]. From 1990 to 2013, the number of fatal cases of hypertensive heart disease increased by $74.1 \%$ worldwide [3]. In addition, 7.6 million premature deaths $(\sim 13.5 \%$ of the global total) and 92 million disability adjusted life years (DALYs; $6.0 \%$ of the global total) were attributed to high

\footnotetext{
* Correspondence: mubul@kku.ac.kr

'Department of Preventive Medicine, School of Medicine, Konkuk University,

1 Hwayang-dong, Gwangjin-gu, Seoul 05029, South Korea

Full list of author information is available at the end of the article
}

blood pressure [4]. In Korea, the death rate associated with hypertension in 2013 was 10.0 per 100000 people [5], and the prevalence rate of hypertension was estimated to be approximately $25.5 \%$, with a total associated medical insurance expenditure of approximately 2.5 trillion won [6]. Despite the high social and economic burdens related to hypertension, the management levels for hypertension had an awareness rate of $65.9 \%$, treatment rate of $60.7 \%$, and control rate of $42.5 \%$ in 2013 [7]. Approaches to increase the awareness, treatment, or control rates for hypertension are in high demand, and it has been suggested that one of the most effective methods is to identify people with hypertension and treat them as soon as possible. 
Likewise, hypertension has high prevalence rate and also it causes a lot of medical expenses. If patients who suffer from hypertension were not treated properly with medication, it would develop complications which cause actual dollars of costs [8]. Hypertensive patients could lower their blood pressure through medical treatment and improvement of their lifestyle. And continual pharmacological treatment for hypertension decreases the hospitalization rate and lowers the risk of complications, such as myocardial infarction and stroke [9]. The government has a responsibility to raise a medication adherence in order to prevent hypertension-induced complications and reduce medical expenditure. Therefore, it is extremely important to figure out the medication adherence. There were several studies that dealt with the rate of visiting a medical institution, the antihypertensive prescription rate medication possession ratio or medical adherence among hypertensive patients [10-12], but they had some limitation like small sample size or restricted study area except one study that covered all hypertensive patients were aged 30 years or more and had received at least one antihypertensive prescription in Taiwan [13]. Furthermore there were no studies which purport for measuring medication adherence in Korea.

The aim of this study were to assess the antihypertensive medication adherence and related factors and to evaluate the status of medical visit and antihypertensive prescription, which are the pre-stage of medication adherence, in order to accurately assess medication adherence among those who were newly diagnosed with hypertension by the General Health Screening (GHS) in Korea 2012. The results could be used as evidence-based data to establish new healthcare policies and strategies for an efficient hypertension management.

\section{Materials and methods Study population}

The inclusion criteria for study subjects were as follows: 1) people who participated in the conducts GHS by the National Health Insurance Service (NHIS) in 2012; 2) participant who had blood pressure with more than 140 in systolic and 90 in diastolic at the first-step screen test and the second-step confirmatory test; 3) people who were diagnosed with hypertension in the result of GHS and were advised to have a pharmacological treatment to manage hypertension in the recommendation of GHS. The exclusion criteria were as follows: 1) participants who visited medical institutions due to hypertension, DM, dyslipidemia, myocardial infarction, stroke etc. as their principal or secondary diagnosis within the previous 3 years of the date of the second-step confirmatory test; 2) participants with a history of diagnosis and/ or pharmacological treatment of hypertension, DM, dyslipidemia, myocardial infarction, stroke etc. based on the questionnaire of the first-step screening test; and 3) participants under 30 years of age at the time of the first-step screening test. The selection process of the final study subjects was shown in Fig. 1. The subjects for the first-step of GHS in 2002 were 15,673,188, of whom $11,419,350(72.8 \%)$ completed the first-step screening test. Of these, 821,973 participants underwent the second-step confirmatory test of hypertension. Based on the results of the second-step confirmatory tests, 109,659 participants were diagnosed with hypertension and were advised to have a pharmacological treatment. Of these, 43,740 were excluded according to the exclusion criteria outlined above. Thus, the final study subjects of the present study were 65,919 .

\section{Study data and variables}

The present study used the qualification data, GHS data of 2012 and data of the insurance claims of medical institutions from January 2009 to December 2014 that were extracted from the NHIS administrative system. The qualification data were used to determine gender (male/female), age, and type of insurance policy; the GHS data were used to determine family history of hypertension, smoking status, alcohol drinking frequency, obesity status, hypertension status, blood glucose level, and blood low-density lipoprotein (LDL)cholesterol level; and the insurance claim data were used to determine the time of the first visit to a medical institution and the number of days prescribed medication for hypertension.

The study subjects were categorized into various subgroups based on their demographic and clinical characteristics for the purposes of comparison. They were categorized based on age (every 10 years of age), insurance policy (regional, employment-based, and medical aid), smoking status (nonsmokers, exsmokers, and smokers), and alcohol drinking frequency (nondrinking, once to twice per week, and more than three times per week). They were also categorized by obesity status according to body mass index (BMI) (normal: < $23 \mathrm{~kg} / \mathrm{m}^{2}$, overweight: 23$24 \mathrm{~kg} / \mathrm{m}^{2}$, obese: $25-29 \mathrm{~kg} / \mathrm{m}^{2}$, and extremely obese: $\geq 30 \mathrm{~kg} / \mathrm{m}^{2}$ ), hypertension level using data from the second-step screening (hypertension stage 1: 140$159 \mathrm{mmHg}$ systolic pressure or $90-99 \mathrm{mmHg}$ diastolic pressure, and hypertension stage $2: \geq 160 \mathrm{mmHg}$ systolic pressure or $\geq 100 \mathrm{mmHg}$ diastolic pressure), and blood glucose level using data from the first-step test (normal: < $126 \mathrm{mg} / \mathrm{dL}$, mild: $126-139 \mathrm{mg} / \mathrm{dL}$, moderate: $140-199 \mathrm{mg} / \mathrm{dL}$, and severe: $\geq 200 \mathrm{mg} / \mathrm{dL}$ ). Blood LDL-cholesterol levels (normal: < $130 \mathrm{mg} / \mathrm{dL}$, mild: $130-159 \mathrm{mg} / \mathrm{dL}$, severe: $\geq 160 \mathrm{mg} / \mathrm{dL}$ ).

The subjects were further divided into subgroups according to the time of their first visit to a 


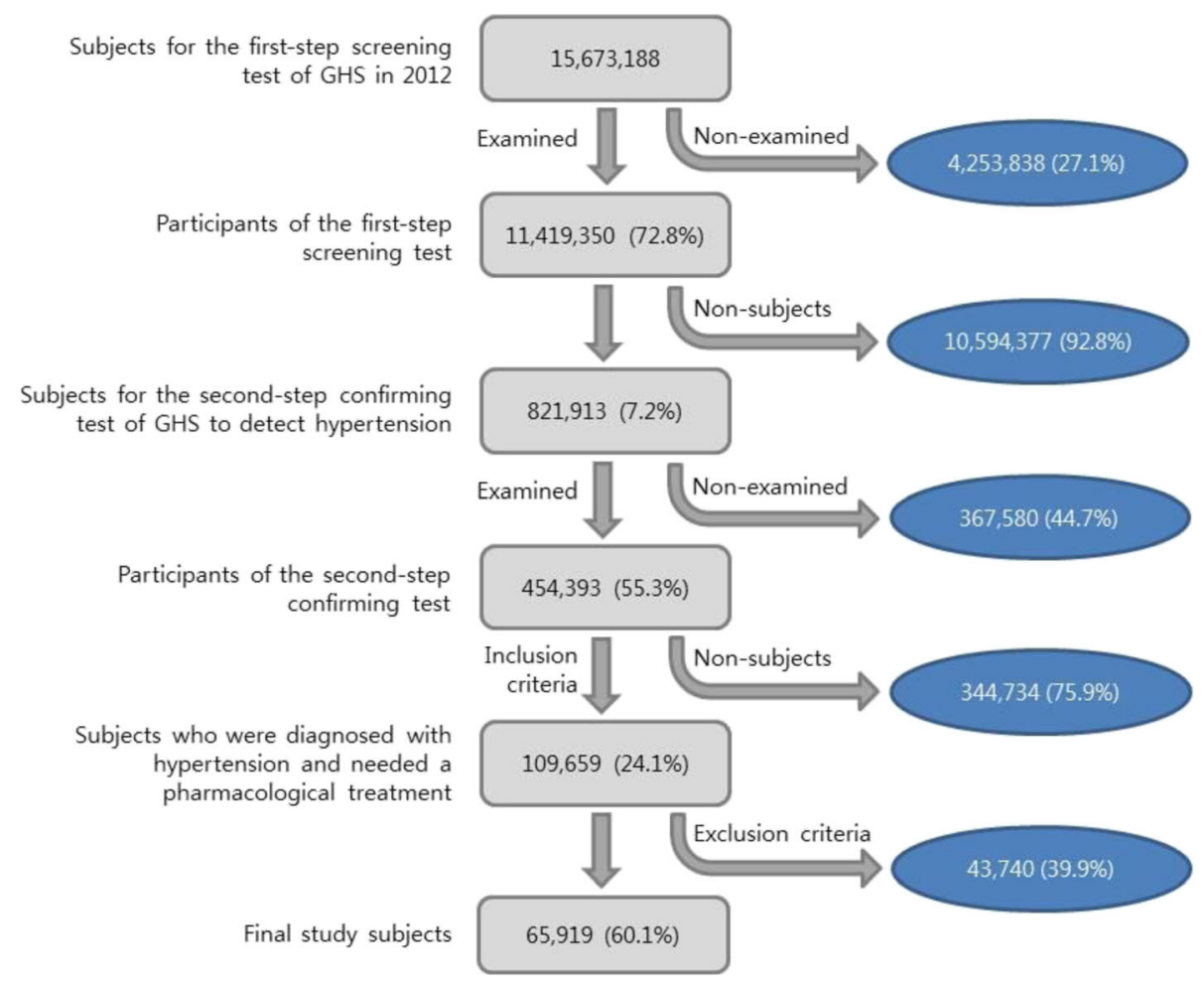

Fig. 1 A selection process of the study subjects

medical institution from the date of the secondstep confirmatory test ( $\leq 90$ days, 91-180 days, and 181-365 days).

\section{Measurement of major indices Visiting rate to medical institution}

A visit to a medical institution was used as an indicator of medical use. In this study, the visiting rate to medical institution was defined as the percentage of hypertensive patients who visited a medical institution as a principle or secondary diagnosis more than one time within 1 year

Number of hypertensive patients who visited a medical institution within 1

Visiting rate to year from the date after diagnosis medical institution $=\frac{\text { year from the date after diagnosis }}{\text { Final number of study subjects }} \times 100$

\section{Antihypertensive prescription rate}

The antihypertensive prescription rate was calculated as the percentage of subjects who received an antihypertensive prescription among the subjects who visited a medical institution.
Antihypertensive prescription rate $=\frac{\begin{array}{l}\text { Number of subjects receiving an } \\ \text { antihypertensive prescription }\end{array}}{\begin{array}{l}\text { Number of study subjects who } \\ \text { visited a medical institution }\end{array}} \times 100$

Medication possession ratio (MPR)

The MPR was defined as the percentage of the sum of days prescribed antihypertensive medication within 1 year from the first prescribed day among the subjects who visited a medical institution over the 365 -day period $[14,15]$. However, we operationally defined MPR as the percentage of sum of the purchased days of antihypertensive medication within 1 year from the first day of purchasing prescribed medication in this study.

Medication possession ratio $=\frac{\begin{array}{l}\text { Sum of the purchased days of } \\ \text { antihypertensive medication within } \\ \text { the period of denominator }(\text { one year })\end{array}}{\begin{array}{c}\text { One year from the first day of } \\ \text { purchasing prescribed medication } \\ (365 \text { days })\end{array}} \times 100$

When the MPR was greater than $100 \%$, it was adjusted to $100 \%$.

\section{Rate of appropriate medication adherence}

Appropriate medication adherence (AMA) was defined as the value of MPR greater than $80 \%[16,17]$. The rate of AMA was calculated as the percentage of subjects who had 
a MPR $\geq 80 \%$ among those who purchased an antihypertensive medication based on the prescription by a physician.

$$
\begin{aligned}
& \text { Rate of appropriate } \\
& \text { medication adherence }
\end{aligned}=\frac{\begin{array}{l}
\text { Number of subjects with } \\
\text { medication possession ratio } \geq 80 \%
\end{array}}{\begin{array}{c}
\text { Number of subjects who purchased } \\
\text { an antihypertensive medication }
\end{array}} \times 100
$$

\section{Data analysis}

The chi-square test, $t$ test, and analysis of variance were used for comparisons within subgroups of the following variables: the rate of visiting a medical institution, the antihypertensive prescription rate, MPR and rate of AMA, respectively. Next, multivariate logistic regression analysis was performed to identify the variables significantly related to visiting a medical institution, antihypertensive prescription rate, and rate of AMA. The odds ratios (OR) and $95 \%$ confidence intervals $(\mathrm{CI})$ of the visiting rate were calculated. Statistical analyses in the present study were conducted using SAS software (version 9.1; SAS Institute Inc., Cary, NC, USA). In all analyses, $p<0.05$ was taken

\begin{tabular}{|c|c|c|c|c|c|c|}
\hline \multirow[t]{2}{*}{ Variables } & & \multicolumn{2}{|c|}{ Medical institution } & \multirow[t]{2}{*}{ Total } & & \multirow[t]{2}{*}{$P$-value } \\
\hline & & Nonvisiting (\%) & Visiting (\%) & & & \\
\hline Total & & $38,024(57.7)$ & $27,895(42.3)$ & 65,919 & $(100)$ & \\
\hline \multirow[t]{2}{*}{ Gender } & Male & $31,068(62.1)$ & $18,927(37.9)$ & 49,995 & $(75.8)$ & $<0.001$ \\
\hline & Female & $6,956(43.7)$ & $8,968(56.3)$ & 15,924 & $(24.2)$ & \\
\hline \multirow[t]{5}{*}{ Age group } & 30-39 years & $10,785(79.1)$ & $2,855(20.9)$ & 13,640 & $(20.7)$ & $<0.001$ \\
\hline & $40-49$ years & $12,898(61.2)$ & $8,187(38.8)$ & 21,085 & $(31.9)$ & \\
\hline & $50-59$ years & $9,817(49.9)$ & $9,877(50.1)$ & 19,694 & $(29.9)$ & \\
\hline & $60-69$ years & $3,432(40.4)$ & $5,055(59.6)$ & 8,487 & $(12.9)$ & \\
\hline & $\geq 70$ year & $1,092(36.2)$ & $1,921(63.8)$ & 3,013 & $(4.6)$ & \\
\hline \multirow[t]{2}{*}{ Family history of hypertension } & Not present & $26,112(64.5)$ & $14,400(35.5)$ & 40,512 & $(81.7)$ & $<0.001$ \\
\hline & Present & $4,990(55.1)$ & 4,059 (44.9) & 9,049 & $(18.3)$ & \\
\hline \multirow[t]{3}{*}{ Smoking status } & Nonsmoker & $14,389(51.6)$ & $13,517(48.4)$ & 27,906 & $(42.4)$ & $<0.001$ \\
\hline & Ex-smoker & $8,325(56.8)$ & $6,335(43.2)$ & 14,660 & $(22.2)$ & \\
\hline & Smoker & $15,295(65.6)$ & $8,032(34.4)$ & 23,327 & $(35.4)$ & \\
\hline \multirow[t]{3}{*}{ Drinking frequency (per week) } & Nondrinking & $10,867(49.1)$ & $11,250(50.9)$ & 22,117 & $(34.4)$ & $<0.001$ \\
\hline & $1-2$ times & $17,585(64.3)$ & $9,775(35.7)$ & 27,360 & $(42.5)$ & \\
\hline & More than 3 times & $8,845(59.3)$ & $6,074(40.7)$ & 14,919 & $(23.1)$ & \\
\hline \multirow[t]{3}{*}{ Insurance type } & Regional & 4,495 (38.6) & $7,159(61.4)$ & 11,654 & $(17.7)$ & $<0.001$ \\
\hline & Employment-based & $33,411(61.9)$ & $20,547(38.1)$ & 53,958 & $(81.8)$ & \\
\hline & Medical aid & $118(38.4)$ & $189(61.6)$ & 307 & $(0.5)$ & \\
\hline \multirow[t]{4}{*}{ BMI level } & Normal & $8,595(56.6)$ & $6,585(43.4)$ & 15,180 & $(23.0)$ & $<0.001$ \\
\hline & Overweight & $9,027(56.1)$ & $7,061(43.9)$ & 16,088 & $(24.4)$ & \\
\hline & Obese & $16,373(57.9)$ & $11,903(42.1)$ & 28,276 & $(42.9)$ & \\
\hline & Extremely obese & $4,026(63.2)$ & $2,345(36.8)$ & 6,371 & $(9.7)$ & \\
\hline \multirow[t]{2}{*}{ Hypertension level } & Hypertension stage 1 & $19,749(62.9)$ & $11,664(37.1)$ & 31,413 & $(47.7)$ & $<0.001$ \\
\hline & Hypertension stage 2 & $18,272(53.0)$ & $16,230(47.0)$ & 34,502 & $(52.3)$ & \\
\hline \multirow[t]{4}{*}{ Blood glucose level } & Normal & $35,742(58.3)$ & $25,570(41.7)$ & 61,312 & $(93.0)$ & $<0.001$ \\
\hline & Mild & $1,109(53.9)$ & $949(46.1)$ & 2,058 & (3.1) & \\
\hline & Moderate & $903(48.4)$ & $964(51.6)$ & 1,867 & $(2.9)$ & \\
\hline & Severe & $265(39.1)$ & $412(60.9)$ & 677 & $(1.0)$ & \\
\hline \multirow[t]{3}{*}{ Blood LDL level } & Normal & 23,781 (59.8) & $16,000(40.2)$ & 39,781 & $(61.5)$ & $<0.001$ \\
\hline & Mild & $9,127(55.9)$ & $7,214(44.1)$ & 16,341 & $(25.3)$ & \\
\hline & Severe & 4,348 (50.9) & 4,188 (49.1) & 8,536 & (13.2) & \\
\hline
\end{tabular}
to indicate statistical significance.

Table 1 Distribution of visiting rates to medical institutions according to the variables 


\section{Results}

Visiting rate to medical institution and its related factors The rate of visiting a medical institution was $42.3 \%$ ( $n=27,895), 37.9 \%$ for males, and $56.3 \%$ for females $(p<0.001)$. The rates of visiting a medical institution according to various variables are shown in Table 1. Based on the results of multivariate logistic regression analysis, the variables significantly associated with visiting a medical institution for hypertension treatment were gender, age, family history of hypertension, smoking status, drinking frequency, insurance type, BMI, hypertension status, blood glucose level and LDL-cholesterol level. The OR and 95\% CI for the rate of visiting a medical institution for hypertension according to the variables evaluated are shown in Table 2 .

Antihypertensive prescription rate and its related factors Of the subjects who visited a medical institution, the antihypertensive prescription rate was $89.1 \% \quad(n=$ $24,861)$. The antihypertensive prescription rates according to the variables evaluated are shown in Table 3. Based on the results of multivariate logistic regression analysis, the variables significantly associated with antihypertensive prescription rate were age, family history of hypertension, smoking status, BMI level, hypertension level, blood glucose level, status, and LDL-cholesterol level. The OR and 95\% CI for the antihypertensive prescription rate according to the variables evaluated are shown in Table 4 .

\section{MPR, rate of AMA, and its related factors}

Of the subjects who received an antihypertensive prescription, the subjects who purchased antihypertensive medication were 24,449 (98.3\%). Among them, the MPR was $70.9 \%$, the rate of AMA was $60.6 \%$, and the MPR and rate of AMA by the variables evaluated are shown in Table 5. Based on the results of multivariate logistic regression analysis, the variables significantly associated with AMA were gender, age, family history of hypertension, smoking status, BMI, hypertension status, and the time of the first visit to a medical institution. The OR and 95\% CI for the rate of AMA according to the variables evaluated are shown in Table 6.

\section{Discussion}

This study was performed to assess the antihypertensive medication adherence in patients who were newly diagnosed with hypertension by the 2012 GHS conducted by the NHIS on commencement of pharmacological treatment and sustainability of antihypertensive medication adherence using the followings indices: rate of visiting a medical institution within 1 year after the
Table 2 Factors associated with visits to medical institutions according to multiple logistic regression analysis

\begin{tabular}{|c|c|c|c|}
\hline & & \multicolumn{2}{|c|}{ Visit to medical institution } \\
\hline & & $\overline{\mathrm{OR}^{a}}$ & $95 \% \mathrm{Cl}^{\mathrm{b}}$ \\
\hline \multirow[t]{2}{*}{ Gender } & Male & 1 & \\
\hline & Female & 1.57 & $1.48-1.67$ \\
\hline \multirow[t]{5}{*}{ Age group } & 30-39 years & 1 & \\
\hline & 40-49 years & 2.05 & $1.93-2.18$ \\
\hline & 50-59 years & 3.28 & $3.07-3.49$ \\
\hline & 60-69 years & 4.81 & $4.43-5.22$ \\
\hline & $\geq 70$ year & 6.37 & $5.63-7.22$ \\
\hline \multirow{2}{*}{$\begin{array}{l}\text { Family history of } \\
\text { hypertension }\end{array}$} & Not present & 1 & \\
\hline & Present & 1.58 & $1.50-1.66$ \\
\hline \multirow[t]{3}{*}{ Smoking status } & Nonsmoker & 1.10 & $1.03-1.16$ \\
\hline & Ex-smoker & 1.26 & $1.19-1.33$ \\
\hline & Smoker & 1 & \\
\hline \multirow{3}{*}{$\begin{array}{l}\text { Drinking frequency } \\
\text { (per week) }\end{array}$} & Nondrinking & 0.98 & $0.92-1.04$ \\
\hline & $1-2$ times & 0.89 & $0.85-0.94$ \\
\hline & More than 3 times & 1 & \\
\hline \multirow[t]{3}{*}{ Insurance type } & Regional & 1.85 & $1.75-1.96$ \\
\hline & Employment-based & 1 & \\
\hline & Medical aid & 2.11 & $1.51-2.96$ \\
\hline \multirow[t]{4}{*}{ BMI level } & Normal & 1 & \\
\hline & Overweight & 1.14 & $1.07-1.20$ \\
\hline & Obese & 1.17 & $1.11-1.23$ \\
\hline & Extremely obese & 1.19 & $1.10-1.29$ \\
\hline \multirow[t]{2}{*}{ Hypertension level } & Hypertension stage 1 & 1 & \\
\hline & Hypertension stage 2 & 1.86 & $1.78-1.94$ \\
\hline \multirow[t]{4}{*}{ Blood glucose level } & Normal & 1 & \\
\hline & Mild & 1.11 & $0.99-1.25$ \\
\hline & Moderate & 1.47 & $1.30-1.66$ \\
\hline & Severe & 2.19 & $1.78-2.70$ \\
\hline \multirow[t]{3}{*}{ Blood LDL level } & Normal & 1. & \\
\hline & Mild & 1.08 & $1.03-1.13$ \\
\hline & Severe & 1.17 & $1.10-1.24$ \\
\hline
\end{tabular}

${ }^{\mathrm{a}} \mathrm{OR}$ odds ratio, ${ }^{\mathrm{b}} \mathrm{Cl}$ confidence interval

date of the second-step confirmatory test, antihypertensive prescription rate within 1 year after the first visit, MPR, and rate of AMA.

For effective management of hypertension, it is imperative to receive an early diagnosis and to visit a medical institution for pharmacological treatment as well as nonpharmacological management by a physician.

First, the rate of visiting a medical institution by the study subjects diagnosed with hypertension was $42.3 \%$ in 
Table 3 Distribution of antihypertensive prescription rates according to the variables

\begin{tabular}{|c|c|c|c|c|c|}
\hline \multirow[t]{2}{*}{ Variables } & & \multicolumn{2}{|c|}{ Antihypertensive prescription } & \multirow[t]{2}{*}{ Total } & \multirow[t]{2}{*}{$P$-value } \\
\hline & & Not receiving (\%) & Receiving (\%) & & \\
\hline Total & & $3,033(10.9)$ & $24,861(89.1)$ & $27,894(100)$ & \\
\hline \multirow[t]{2}{*}{ Gender } & Male & $1,994(10.5)$ & $16,933(89.5)$ & $18,927(67.9)$ & 0.009 \\
\hline & Female & $1,039(11.6)$ & $7,928(88.4)$ & $8,967(32.1)$ & \\
\hline \multirow[t]{5}{*}{ Age group } & 30-39 years & $415(14.5)$ & $2,440(85.5)$ & $2,855(10.2)$ & $<0.001$ \\
\hline & 40-49 years & $781(9.5)$ & $7,406(90.5)$ & $8,187(29.4)$ & \\
\hline & $50-59$ years & $1,000(10.1)$ & 8,877 (89.9) & $9,877(35.4)$ & \\
\hline & 60-69 years & $594(11.8)$ & $4,461(88.2)$ & $5,055(18.1)$ & \\
\hline & $\geq 70$ year & $243(12.7)$ & $1,677(87.3)$ & $1,920(6.9)$ & \\
\hline \multirow{2}{*}{$\begin{array}{l}\text { Family history of } \\
\text { hypertension }\end{array}$} & Not present & $1,615(11.2)$ & $12,784(88.8)$ & $14,399(78.0)$ & 0.057 \\
\hline & Present & $412(10.2)$ & $3,647(89.8)$ & $4,059(22.0)$ & \\
\hline \multirow[t]{3}{*}{ Smoking status } & Nonsmoker & 1,568 (11.6) & $11,984(88.4)$ & $13,516(48.5)$ & $<0.001$ \\
\hline & Ex-smoker & $699(11.0)$ & $5,636(89.0)$ & $6,335(22.7)$ & \\
\hline & Smoker & $765(9.5)$ & $7,267(90.5)$ & $8,032(28.8)$ & \\
\hline \multirow{3}{*}{$\begin{array}{l}\text { Drinking frequency } \\
\text { (per week) }\end{array}$} & Nondrinking & $1,314(11.7)$ & $9,935(88.3)$ & $11,249(41.5)$ & $<0.001$ \\
\hline & $1-2$ times & 1,084 (11.1) & 8,691 (88.9) & $9,775(36.1)$ & \\
\hline & More than 3 times & $569(9.4)$ & $5,505(90.6)$ & $6,074(22.4)$ & \\
\hline \multirow[t]{3}{*}{ Insurance type } & Regional & 757 (10.6) & $6,402(89.4)$ & $7,159(25.7)$ & 0.435 \\
\hline & Employment-based & $2,259(11.0)$ & $18,287(89.0)$ & $20,546(73.6)$ & \\
\hline & Medical aid & $17(9.0)$ & $172(91.0)$ & $189(0.7)$ & \\
\hline \multirow[t]{4}{*}{ BMI level } & Normal & 789 (12.0) & $5,796(88.0)$ & $6,585(23.6)$ & $<0.001$ \\
\hline & Overweight & $811(11.5)$ & $6,250(88.5)$ & $7,061(25.3)$ & \\
\hline & Obese & $1,228(10.3)$ & $10,608(89.7)$ & $11,902(42.7)$ & \\
\hline & Extremely obese & $205(8.7)$ & 2,090 (91.3) & 2,354 (8.4) & \\
\hline \multirow[t]{2}{*}{ Hypertension level } & Hypertension stage 1 & $1,620(13.9)$ & $10,043(86.1)$ & $11,663(41.8)$ & $<0.001$ \\
\hline & Hypertension stage 2 & $1,413(8.7)$ & $14,817(91.3)$ & $16,230(58.2)$ & \\
\hline \multirow[t]{4}{*}{ Blood glucose level } & Normal & $2,820(11.0)$ & $22,749(89.0)$ & $25,569(91.7)$ & 0.007 \\
\hline & Mild & $97(10.2)$ & $852(89.8)$ & 949 (3.3) & \\
\hline & Moderate & $90(9.3)$ & $874(90.7)$ & $964(3.5)$ & \\
\hline & Severe & $26(6.3)$ & $386(93.7)$ & $412(1.5)$ & \\
\hline \multirow[t]{3}{*}{ Blood LDL level } & Normal & $1,603(10.0)$ & $14,397(90.0)$ & $16,000(58.4)$ & $<0.001$ \\
\hline & Mild & $820(11.4)$ & 6,394 (88.6) & $7,214(26.3)$ & \\
\hline & Severe & $580(13.8)$ & $3,607(86.2)$ & $4,187(15.3)$ & \\
\hline
\end{tabular}

Data are expressed as the number (\%)

$P$-value from chi-square test for binary outcomes comparing a difference between of not receiving prescription and receiving prescription

this study. In addition, the rate of visiting a medical institution was $20.9 \%$ for study subjects in their 30 s. These results could be interpreted as the early finding of chronic disease such as hypertension by GHS did not induce the early treatment effectively. These results were related with the fact that the rates of awareness and treatment for hypertension in the 30s in Korea were 19.1 and $12.4 \%$ [18]. In order to manage hypertension and prevent its complications, first of all, there is a need to alert those with risk factors for hypertension and those diagnosed but who not visit a medical institution to improve the awareness rate. In addition, the rate of visiting a medical institution within 1 year of diagnosis was higher in women than men, those of advance age, those with a family history of hypertension, ex-smokers, those with a high BMI, those with more severe hypertension, or those with other chronic diseases, such as diabetes or hyperlipidemia.

Next, among subjects who visited a medical institution, 89.1\% received the antihypertensive prescription by a physician. The antihypertensive prescription rate was low 
Table 4 Factors associated with antihypertensive prescription according to multiple logistic regression analysis

\begin{tabular}{|c|c|c|c|}
\hline & & \multicolumn{2}{|c|}{$\begin{array}{l}\text { Antihypertensive } \\
\text { prescription }\end{array}$} \\
\hline & & $\overline{\mathrm{OR}^{\mathrm{a}}}$ & $95 \% \mathrm{Cl}^{\mathrm{b}}$ \\
\hline \multirow[t]{2}{*}{ Gender } & Male & 1 & \\
\hline & Female & 1.03 & $0.89-1.18$ \\
\hline \multirow[t]{5}{*}{ Age group } & 30-39 years & 1 & \\
\hline & 40-49 years & 1.83 & $1.56-2.13$ \\
\hline & $50-59$ years & 1.92 & $1.64-2.25$ \\
\hline & $60-69$ years & 1.82 & $1.52-2.19$ \\
\hline & $\geq 70$ year & 1.50 & $1.18-1.90$ \\
\hline \multirow{2}{*}{$\begin{array}{l}\text { Family history of } \\
\text { hypertension }\end{array}$} & Not present & 1 & \\
\hline & Present & 1.15 & $1.02-1.30$ \\
\hline \multirow[t]{3}{*}{ Smoking status } & Nonsmoker & 0.78 & $0.68-0.90$ \\
\hline & Ex-smoker & 0.86 & $0.75-0.99$ \\
\hline & Smoker & 1 & \\
\hline \multirow{3}{*}{$\begin{array}{l}\text { Drinking frequency } \\
\text { (per week) }\end{array}$} & Nondrinking & 0.94 & $0.81-1.09$ \\
\hline & $1-2$ times & 0.87 & $0.76-1.00$ \\
\hline & More than 3 times & 1 & \\
\hline \multirow[t]{3}{*}{ Insurance type } & Regional & 0.93 & $0.82-1.04$ \\
\hline & Employment-based & 1 & \\
\hline & Medical aid & 1.16 & $0.58-2.31$ \\
\hline \multirow[t]{4}{*}{ BMI level } & Normal & 1 & \\
\hline & Overweight & 1.12 & $0.98-1.28$ \\
\hline & Obese & 1.32 & $1.17-1.49$ \\
\hline & Extremely obese & 1.69 & $1.37-2.07$ \\
\hline \multirow[t]{2}{*}{ Hypertension level } & Hypertension stage 1 & 1 & \\
\hline & Hypertension stage 2 & 1.72 & $1.56-1.89$ \\
\hline \multirow[t]{4}{*}{ Blood glucose level } & Normal & 1 & \\
\hline & Mild & 0.87 & $0.67-1.13$ \\
\hline & Moderate & 0.99 & $0.75-1.31$ \\
\hline & Severe & 1.86 & $1.08-3.22$ \\
\hline \multirow[t]{3}{*}{ Blood LDL level } & Normal & 1 & \\
\hline & Mild & 0.82 & $0.73-0.91$ \\
\hline & Severe & 0.66 & $0.58-0.76$ \\
\hline
\end{tabular}

${ }^{a} \mathrm{OR}$ odds ratio, ${ }^{\mathrm{b}} \mathrm{Cl}$ confidence interval

among relatively healthy subjects, i.e., those in their 30s with no family history of hypertension, and those with a normal BMI. The guidelines of JNC-8 and European Society of Hypertension address treatment according to hypertension level and risk factors [19, 20]. Lifestyle changes are primarily recommended for those in low- or medium-risk groups. Based on these guidelines, physicians often recommended lifestyle changes instead of antihypertensive medication for subjects who were relatively healthy and belong to the low-risk group.
Finally, among subjects who received the antihypertensive prescription, $98.3 \%$ purchased antihypertensive medication. Among them, the MPR was $70.9 \%$ and the rate of AMA was $60.6 \%$. Medication adherence of women $(62.5 \%)$ was better than that of men (58.4\%), that of advanced age ( $\geq 70$ : $59.9 \%$ ), that with a relevant family history, that with a high BMI, that with high blood pressure, and that with a delayed first visit to a medical institution. There were some studies about medication adherence for hypertension. For example, Rolnick et al. revealed that medication adherence was better in men $(70.5 \%)$ than in women $(68.8 \%)$, those of advanced age ( $\geq 70: 70.5 \%)$ in the U.S, [10]. Yang et al. reported that medication adherence was $43.5 \%$ and better in men (47.2\%) than in women (40.3\%), those of advanced age $(\geq 70$ : $55.6 \%$ ), those with having a knowledge about hypertension needs lifelong medical treatment (47.1\%) in Beijing [11]. And Inkster et al. found that medication adherence was better in men $(87 \%)$ than in women $(85 \%)$, those of a advanced age ( $\geq 70: 91 \%)$, those with high comorbidities (2 +: 91\%) in the UK [12]. Lee et al. showed that approximately $53 \%$ of the patients had high compliance with antihypertensive medication in Taiwan [13]. Since each study and disease has its own definitions of the evaluation methods, medication adherence, and follow-up periods for medication adherence, it is not easy to compare the results directly among studies. Nevertheless, the MPR for hypertension treatment in this study was higher than that of Taiwan but lower than those of western countries. Meanwhile, age and comorbidity were known as an important factors related to expectations regarding treatment, and attitude to taking medication [21,22]. Similarly, the rates of visiting a medical institution and of AMA were low among younger subjects and some subgroups, such as subjects who were overweight or had higher LDL-cholesterol levels, had higher rates of AMA in this study. The rate of medication adherence was also high when the satisfaction rate regarding medication counseling was high [23], while "forgetting to take the medication" was the principal reason for decreased medication adherence [24]. According to a previous systematic review study regarding the MPR and the rate of AMA for chronic diseases [25], 12-month MPR was $67 \%$ and the rate of AMA was $64 \%$ in hypertension, MPR was $76 \%$ and the rate of AMA was $58 \%$ in diabetes, and MPR was $74 \%$ and the rate of AMA was $51 \%$ in dyslipidemia. To improve medication adherence, it is necessary for a physician to promote and educate hypertension patients themselves to recognize the importance of medication treatment, and to provide appropriate counseling services them to change the health behaviors like smoking, physical activities etc.

This study had several limitations. First, as the data from GHS and health insurance claims were used, this study had the limitation of using secondary data. Therefore, we could not examine the characteristics of the 
Table 5 Distribution of the medication possession ratio and appropriate medication adherence according to the variables

\begin{tabular}{|c|c|c|c|c|c|c|c|}
\hline \multirow[t]{2}{*}{ Variables } & & \multicolumn{2}{|c|}{ Medication possession ratio } & \multicolumn{4}{|c|}{ Appropriate medication adherence } \\
\hline & & Mean (SD) & $P$-value & $\mathrm{MPR}<80 \%$ & $M P R \geq 80 \%$ & Total & $P$-value \\
\hline Total & & $70.9(36.4)$ & & $9,640(39.4)$ & $14,809(60.6)$ & $24,449(100)$ & \\
\hline \multirow[t]{2}{*}{ Gender } & Male & $69.1(37.1)$ & $<0.001$ & $6,919(41.6)$ & $9,713(58.4)$ & $16,632(68.0)$ & $<0.001$ \\
\hline & Female & $74.7(34.5)$ & & $2,721(34.8)$ & $5,096(65.2)$ & $7,817(32.0)$ & \\
\hline \multirow[t]{5}{*}{ Age group } & 30-39 years & $57.9(39.3)$ & $<0.001$ & $1,306(54.9)$ & 1,071 (45.1) & $2,377(9.7)$ & $<0.001$ \\
\hline & $40-49$ years & $70.4(36.2)$ & & $2,939(40.4)$ & $4,342(59.6)$ & $7,281(29.8)$ & \\
\hline & $50-59$ years & $73.2(35.4)$ & & $3,180(36.3)$ & $5,577(63.7)$ & $8,757(35.8)$ & \\
\hline & $60-69$ years & $74.2(35.1)$ & & $1,555(35.5)$ & $2,832(64.5)$ & $4,387(17.9)$ & \\
\hline & $\geq 70$ year & $69.8(37.5)$ & & $660(40.1)$ & $987(59.9)$ & $1,647(6.7)$ & \\
\hline \multirow{2}{*}{$\begin{array}{l}\text { Family history of } \\
\text { hypertension }\end{array}$} & Not present & $71.7(35.9)$ & $<0.001$ & $4,870(38.7)$ & $7,716(61.3)$ & $12,586(77.8)$ & $<0.001$ \\
\hline & Present & $74.2(34.8)$ & & $1,259(35.0)$ & $2,336(65.0)$ & $3,595(22.2)$ & \\
\hline \multirow[t]{3}{*}{ Smoking status } & Nonsmoker & $72.6(35.6)$ & $<0.001$ & $4,415(37.5)$ & $7,358(62.5)$ & $11,773(48.2)$ & $<0.001$ \\
\hline & Ex-smoker & $73.2(35.6)$ & & $2,003(36.2)$ & $3,534(63.8)$ & $5,537(22.7)$ & \\
\hline & Smoker & $66.2(37.9)$ & & $3,220(45.2)$ & $3,909(54.8)$ & $7,129(29.2)$ & \\
\hline \multirow{3}{*}{$\begin{array}{l}\text { Drinking frequency } \\
\text { (per week) }\end{array}$} & Nondrinking & $73.1(35.4)$ & $<.0001$ & $3,578(36.6)$ & $6,209(63.4)$ & $9,787(41.2)$ & $<0.001$ \\
\hline & $1-2$ times & $69.6(36.9)$ & & $3,495(40.9)$ & $5,042(59.1)$ & $8,537(36.0)$ & \\
\hline & More than 3 times & $69.3(36.9)$ & & $2,248(41.6)$ & $3,163(58.4)$ & $5,411(22.8)$ & \\
\hline \multirow[t]{3}{*}{ Insurance type } & Regional & $70.5(36.4)$ & 0.340 & $2,512(39.9)$ & $3,791(60.1)$ & 6,303 (25.8) & 0.504 \\
\hline & Employment-based & 71.0 (36.4) & & 7,055 (39.3) & $10,919(60.7)$ & $17,974(73.5)$ & \\
\hline & Medical aid & $70.3(34.7)$ & & $73(42.4)$ & 99 (57.6) & $172(0.7)$ & \\
\hline \multirow[t]{4}{*}{ BMI level } & Normal & $69.7(36.9)$ & $<0.001$ & $2,341(41.0)$ & $3,367(59.0)$ & $5,708(23.4)$ & $<0.001$ \\
\hline & Overweight & $71.9(36.1)$ & & $2,341(38.0)$ & $3,811(62.0)$ & $6,152(25.2)$ & \\
\hline & Obese & $71.8(35.9)$ & & $4,036(38.5)$ & $6,461(61.5)$ & $10,497(42.9)$ & \\
\hline & Extremely obese & $66.4(37.8)$ & & $922(44.1)$ & $1,169(55.9)$ & 2,091 (8.6) & \\
\hline \multirow[t]{2}{*}{ Hypertension level } & Hypertension stage 1 & $69.3(37.1)$ & $<0.001$ & $4,052(41.1)$ & $5,809(58.9)$ & $9,861(40.3)$ & $<0.001$ \\
\hline & Hypertension stage 2 & 71.9 (35.8) & & $5,587(38.3)$ & $9,000(61.7)$ & $14,587(59.7)$ & \\
\hline \multirow[t]{4}{*}{ Blood glucose level } & Normal & $70.9(36.4)$ & 0.228 & $8,814(39.4)$ & $13,554(60.6)$ & $22,368(91.5)$ & 0.670 \\
\hline & Mild & $69.9(37.2)$ & & 331 (39.3) & $511(60.7)$ & $842(3.4)$ & \\
\hline & Moderate & $69.6(36.5)$ & & $351(41.0)$ & $504(59.0)$ & $855(3.5)$ & \\
\hline & Severe & 73.9 (33.9) & & $144(37.5)$ & $240(62.5)$ & $384(1.6)$ & \\
\hline \multirow[t]{3}{*}{ Blood LDL level } & Normal & 70.6 (36.6) & 0.355 & $5,590(39.5)$ & $8,547(60.5)$ & $14,137(58.9)$ & 0.716 \\
\hline & Mild & $71.3(36.2)$ & & $2,474(39.3)$ & $3,828(60.7)$ & 6,302 (26.3) & \\
\hline & Severe & 71.4 (35.9) & & $1,381(38.8)$ & $2,177(61.2)$ & $3,558(14.8)$ & \\
\hline \multirow{3}{*}{$\begin{array}{l}\text { Time of the first visit to a } \\
\text { medical institution (days) }\end{array}$} & Within 90 & $69.7(37.0)$ & 0.301 & $7,624(40.7)$ & $11,108(59.3)$ & $18,732(76.6)$ & $<0.001$ \\
\hline & $91-180$ & $75.1(33.7)$ & & 779 (34.6) & $1,474(65.4)$ & $2,253(9.2)$ & \\
\hline & After 181 & $74.5(34.2)$ & & $1,237(35.7)$ & 2,227 (64.3) & $3,464(14.2)$ & \\
\hline
\end{tabular}

Medication possession ratio's data are expressed as the mean (SD)

Appropriate medication adherence's data are expressed as the number (\%)

$P$-value from chi-square test for binary outcomes comparing a difference between of MPR $\geq 80 \%$ and MPR $<80 \%$

study population, such as knowledge, attitude, or access to medical institutions, etc. Second, this study dealt only with a study population with primary or secondary disease codes for hypertension. Therefore, it is likely that some data were missing, because they were not claimed as primary or secondary disease codes. However, the chance of this was very low because the study population was diagnosed with hypertension for the first time through GHS in 2012. Third, medication adherence was determined as the MPR based on the purchase of antihypertension medication that was prescribed by a physician. MPR cannot be used to verify the intake of the 
Table 6 Factors associated with the appropriate medication adherence according to multiple logistic regression analysis

\begin{tabular}{|c|c|c|c|}
\hline & & \multicolumn{2}{|c|}{$\begin{array}{l}\text { Appropriate medication } \\
\text { adherence }\end{array}$} \\
\hline & & $\overline{O R^{a}}$ & $95 \% \mathrm{Cl}^{\mathrm{b}}$ \\
\hline \multirow[t]{2}{*}{ Gender } & Male & 1 & \\
\hline & Female & 1.22 & $1.10-1.34$ \\
\hline \multirow[t]{5}{*}{ Age group } & 30-39 years & 1 & \\
\hline & 40-49 years & 1.72 & $1.53-1.92$ \\
\hline & $50-59$ years & 2.17 & $1.93-2.43$ \\
\hline & 60-69 years & 2.28 & $1.99-2.62$ \\
\hline & $\geq 70$ year & 2.00 & $1.66-2.41$ \\
\hline \multirow{2}{*}{$\begin{array}{l}\text { Family history } \\
\text { of hypertension }\end{array}$} & Not present & 1 & \\
\hline & Present & 1.26 & $1.16-1.37$ \\
\hline \multirow[t]{3}{*}{ Smoking status } & Nonsmoker & 1.07 & $0.97-1.18$ \\
\hline & Ex-smoker & 1.30 & $1.19-1.43$ \\
\hline & Smoker & 1 & \\
\hline \multirow{3}{*}{$\begin{array}{l}\text { Drinking frequency } \\
\text { (per week) }\end{array}$} & Nondrinking & 1.11 & $1.00-1.23$ \\
\hline & $1-2$ times & 1.05 & $0.96-1.14$ \\
\hline & More than 3 times & 1 & \\
\hline \multirow[t]{3}{*}{ Insurance type } & Regional & 0.93 & $0.86-1.01$ \\
\hline & Employment-based & 1 & \\
\hline & Medical aid & 0.78 & $0.50-1.19$ \\
\hline \multirow[t]{4}{*}{ BMI level } & Normal & 1 & \\
\hline & Overweight & 1.12 & $1.01-1.23$ \\
\hline & Obese & 1.14 & $1.04-1.25$ \\
\hline & Extremely obese & 1.03 & $0.90-1.18$ \\
\hline \multirow[t]{2}{*}{ Blood pressure level } & Hypertension stage 1 & 1 & \\
\hline & Hypertension stage 2 & 1.24 & $1.16-1.33$ \\
\hline \multirow[t]{4}{*}{ Blood glucose level } & Normal & 1 & \\
\hline & Mild & 0.89 & $0.74-1.07$ \\
\hline & Moderate & 0.94 & $0.78-1.14$ \\
\hline & Severe & 1.24 & $0.93-1.66$ \\
\hline \multirow[t]{3}{*}{ Blood LDL level } & Normal & 1 & \\
\hline & Mild & 0.91 & $0.84-0.98$ \\
\hline & Severe & 0.96 & $0.87-1.06$ \\
\hline \multirow{3}{*}{$\begin{array}{l}\text { Time of the first } \\
\text { visit to a medical } \\
\text { institution (days) }\end{array}$} & Within 90 & 1 & \\
\hline & $91-180$ & 1.29 & $1.15-1.44$ \\
\hline & After 181 & 1.32 & $1.20-1.44$ \\
\hline
\end{tabular}

medications. However, the prescription is significant as the first step in taking a medication, and there have been reports that the MPR that use the prescription is a good index for verifying medication adherence [26]. Furthermore, it is almost impossible to verify medication compliance in studies based on massive databases. In order to overcome the limitation of prescription that can not verify medication compliance, we used the purchase of antihypertension medication that is the next step after receiving the antihypertensive prescription. Of the subjects who received an antihypertensive prescription, the rate of the purchase of antihypertensive medication was $98.3 \%$ in this study. MPR and the rate of AMA based on the prescription were 69.9 and $59.7 \%$ (not described in the result) but those of based on the purchase were 70.9 and $60.6 \%$. We could find there was the difference values of MPR and the rate of AMA between the data. In fact, patients who purchased the medication take more positive behavior on treatment than patients who were just prescribed medication.

This study showed that the antihypertensive medication adherence in patients who were newly diagnosed with hypertension was not relatively high in Korea. First of all, those diagnosed with hypertension should visit a medical institution to increase the MPR and rate of AMA. Medical institutions that diagnose hypertension should notify and educate hypertensive patients of their medical situation and encourage them to participate actively in treatment. Next, those diagnosed with hypertension should follow the directions of their physicians and cooperate to manage their hypertension. NHIS should make and support an environment in which medical institutions and those diagnosed with hypertension can fulfill their roles.

\section{Acknowledgements \\ This work was supported by Konkuk University in 2014}

\section{Authors' contributions}

$\mathrm{HJ}$ mainly wrote the manuscript; HK contributed to conception and design of study, acquisition of data and interpretation of data. JHL, HMA and VK conducted data clearing and data analysis. $\mathrm{KL}$ and SAS provided the statistical support contributed to the interpretation of study results. All authors read and approved the final manuscript.

\section{Competing interests}

The authors declare that they have no competing interests.

\section{Ethics approval and consent to participate}

This article does not contain any studies with human participants performed by any of the authors. This study was reviewed and approved by the Institutional Review Board of Konkuk University Hospital (KUH1260021).

\section{Publisher's Note}

Springer Nature remains neutral with regard to jurisdictional claims in published maps and institutional affiliations.

\section{Author details \\ ${ }^{1}$ Department of Preventive Medicine, School of Medicine, Konkuk University, 1 Hwayang-dong, Gwangjin-gu, Seoul 05029, South Korea. Bigdata Steering Department, National Health Insurance Service, Wonju, South Korea. ${ }^{3}$ Department of Dental Hygiene, Suwon Women's University, Suwon, South Korea.}

Received: 16 August 2016 Accepted: 4 March 2017

Published online: 17 March 2017

\section{References}

1. Mainous AG, Everett CJ, Liszka H, King DE, Egan BM. Prehypertension and mortality in a nationally representative cohort. Am J Cardiol. 2004;94(12): 1496-500.

2. Williams B. The year in hypertension. J Am Coll Cardiol. 2006;48(8):1698-711. 
3. GBD 2013 Mortality and Causes of Death Collaborators. Global, regional, and national age-sex specific all-cause and cause-specific mortality for 240 causes of death, 1990-2013: a systematic analysis for the Global Burden of Disease Study 2013. Lancet. 2015:385(9963):117-71.

4. Lawes $\mathrm{CM}$, Vander HS, Rodgers A. Global burden of blood pressure-related disease, 2001. Lancet. 2008;371(9623):1513-8.

5. Statistics Korea. The cause of death in Korea. 2014. http://www.index.go.kr/ potal/main/EachDtlPageDetail.do?idx_cd=1012. Accessed 10 Nov 2015.

6. National Health Insurance Service. National health insurance statistical year book. 2014. http.//www.nhis.or.kr/menu/boardRetriveMenuSet.xx?menuld=F3321. Accessed 11 Dec 2015.

7. Ministry of Health \& Welfare and Korea Center for Disease Control and Prevention. The ${ }^{6}$ th (year 2) Korea National Health and Nutrition Examination Survey. Osong: 2009. p. 52-3.

8. Kim SO. Medication adherence of elderly with hypertension and/or diabetes mellitus and its influencing factors. Korean J Clin Pharm. 2011;21(2):81-9.

9. Charles $\mathrm{H}, \mathrm{Good} \mathrm{CB}$, Hanusa HB, Chang HC, Whittle J. Racial differences in adherence to cardiac medications. J Natl Med Assoc. 2003;95(1):17-22.

10. Rolnick SJ, Pawloski PA, Hedblom BD, Asche SE, Bruzek RJ. Patient characteristics associated with medication adherence. Clin Med Res. 2013; 11(2):54-65.

11. Yang S, He C, Zhang X, Sun K, Wu S, Sun X, et al. Determinants of antihypertensive adherence among patients in Beijing: application of the health belief model. Patient Educ Couns. 2016;99(11):1894-900.

12. Inkster ME, Donnan PT, MacDonald TM, Sullivan FM, Fahey T. Adherence to antihypertensive medication and association with patient and practice factors. J Hum Hypertens. 2006;20(4):295-7.

13. Lee $\mathrm{CY}$, Huang $\mathrm{CC}$, Shih $\mathrm{HC}$, Huang $\mathrm{KH}$. Factors influencing antihypertensive medication compliance in Taiwan: a nationwide population-based study. Eur J Prev Cardiol. 2013;20(6):930-7.

14. Cramer JA. A systematic review of adherence with medications for diabetes. Diabetes Care. 2004;27(5):1218-24.

15. Karve $S$, Cleves MA, Helm M, Hudson TJ, West DS, Martin BC. An empirical basis for standardizing adherence measures derived from administrative claims data among diabetic patients. Med Care. 2008:46(11):1125-33.

16. Brown MT, Bussell JK. Medication adherence: WHO cares? Mayo Clin Proc. 2011;86:304-14.

17. Clifford S, Perez-Nieves M, Skalicky AM, Reaney M, Coyne KS. A systematic literature review of methodologies used to assess medication adherence in patients with diabetes. Curr Med Res Opin. 2014;30(6):1071-85.

18. Fauci A, Braunwald E, Kasper D, Hauser S, Longo D, Jameson J, et al. Harrison's principles of internal medicine. 17th ed. New York: McGraw-Hill; 2009. p. 1871-87.

19. Paul AJ, Suzanne O, Barry LC, William CC, Cheryl D, Joel H, et al. 2014 evidence-based guideline for the management of high blood pressure in adults report from the panel members appointed to the Eighth Joint National Committee (JNC 8). JAMA. 2014;311(5):507-20.

20. Guideline Committee. 2003 European Society of Hypertension-European Society of cardiology guidelines for the management of arterial hypertension. J Hypertens. 2003:21:1011-53.

21. Briesacher BA, Andrade SE, Fouayzi H, Chan KA. Comparison of drug adherence rates among patients with seven different medical conditions. Pharmacotherapy. 2008;28(4):437-43.

22. Lee $\mathrm{E}$, Park J. Analysis of factors affecting medication compliance of outpatients. Qual Improv Health Care. 2002;9(2):164-75.

23. Heo J, Kim S, Kim J, Huh S. Effect of patient's satisfaction with pharmacist's medication counseling on medication compliance among outpatients. Korean J Clin Pharm. 2009;19(2):110-9.

24. Hsu C, Lemon JM, Wong ES, Carson-Cheng E, Perkins M, Nordstrom MS, et al. Factors affecting medication adherence: patient perspectives from five veterans affairs facilities. BMC Health Serv Res. 2014:14:533.

25. Cramer JA, Benedict A, Muszbek N, Keskinaslan A, Khan ZM. The significance of compliance and persistence in the treatment of diabetes, hypertension and dyslipidemia. Int J Clin Pract. 2008;62(1):76-87.

26. Lau DT, Nau DP. Oral antihyperglycemic medication nonadherence and subsequent hospitalization among individuals with type 2 diabetes. Diabetes Care. 2004;27(9):2149-53.

\section{Submit your next manuscript to BioMed Central and we will help you at every step:}

- We accept pre-submission inquiries

- Our selector tool helps you to find the most relevant journal

- We provide round the clock customer support

- Convenient online submission

- Thorough peer review

- Inclusion in PubMed and all major indexing services

- Maximum visibility for your research

Submit your manuscript at www.biomedcentral.com/submit
Biomed Central 